\title{
INFLUENCE OF THE SCN1A IVS5N + 5 G>A POLYMORPHISM ON THERAPY WITH CARBAMAZEPINE FOR EPILEPSY
}

\author{
Sterjev $Z^{1},{ }^{*}$, Kiteva $\mathrm{G}^{2}$, Cvetkovska $\mathrm{E}^{2}$, Petrov $\mathrm{I}^{2}$, Kuzmanovski $\mathrm{I}^{2}$, Ribarska $\mathrm{TJ}^{3}$, \\ Nestorovska KA ${ }^{1}$, Matevska ${ }^{1}$,Trajkovik-Jolevska $\mathrm{S}^{3}$, Dimovski AJ ${ }^{1}$, Suturkova, $\mathrm{Lj}^{1}$
}

*Corresponding Author: Zoran Sterjev, M. Sei. Pharm Institute of Pharmaceutical Chemistry, Faculty of Pharmacy, University “St. Cyril and Methodius," str. Vodnjanska 17, 1000 Skopje, Republic of Macedonia; Tel./Fax:+38-923-120-229; E-mail: zost@ff.ukim.edu.mk

\section{ABSTRACT}

Carbamazepine (CBZ) blocks neuronal sodium channels in a voltage- and frequency-dependent manner, delaying the recovery of the channels from the inactivated state, reducing the number of action potentials within a burst, and decreasing burst duration. The $\alpha$-subunit of the first neuronal sodium channel (SCN1A) is a major gene in different epilepsies. A synonymous polymorphism (SCN1A IVS5N $+5 \mathrm{G}>\mathrm{A}$ or rs3812718) is common in exon 5 of this gene. Mutations in the $\alpha$-unit of this gene are associated with CBZ-resistant epilepsy and a higher maintenance dose of CBZ. We have investigated the association of this single nucleotide polymorphism (SNP) and epilepsy, efficacy and dose-dependence of CBZ therapy in 147 adult Macedonian patients and 137 non epileptic controls. No significant differences in allelic frequencies and genotype distribution were found between patients and controls $(p$ $=0.94278$ ), or between CBZ-responsive and unresponsive patients $(p=0.55449)$. An association between the A allele and a higher maintenance dose in CBZ-responsive patients was detected. No statistical difference was found between the plasma levels

Institute for Pharmaceutical Chemistry, Faculty of Pharmacy, University "St. Cyril and Methodius," Skopje, Republic of Macedonia

2 Clinic of Neurology, Faculty of Medicine, University "St. Cyril and Methodius," Skopje, Republic of Macedonia

Institute for Pharmaceutical Analysis, Faculty of Pharmacy, University "St. Cyril and Methodius,"Skopje, Republic of Macedonia of CBZ and genotype of patients receiving the same dose, indicating that the variant exerts its effect at the level of receptor responsiveness. The predictive value of pretreatment testing showed a minor insignificant difference between patients with different genotypes, primarily due to a small number of patients.

Keywords: Carbamazepine (CBZ); Epilepsy; Pharmacoresistant epilepsy; SCN1A polymorphism

\section{INTRODUCTION}

Voltage-gated sodium channels that are responsible for enabling neurons to fire action potentials at a high frequency are important targets for the commonly used anti epileptic drugs such as Carbamazepine (CBZ), Oxcarbazepine, Phenytoin, Lamotrigin and Zonisamide. The $\alpha$-subunit of the first neuronal sodium channel (SCN1A) gene regulates the activity of one of the ion channels in the brain, the sodium channel, which may exhibit different electrophysiological properties in patients with pharmacoresistant epilepsy as compared to responsive patients [1].

Carbamazepine is a commonly used anti convulsive drug for the treatment of partial, generalized tonic-clonic and mixed seizures. It blocks neuronal sodium channels in a voltage- and frequency-dependent manner, delaying their recovery from the inactivated state, reducing the number of action potentials within a burst, and decreasing burst duration. Sodium channels are heteromultimeric complexes that comprise the large (approximately 260 
Table 1. Pharmacogenetic studies on effects of SCN1A IVS5N + 5 G>A polymorphism on CBZ therapy.

\begin{tabular}{|c|c|c|c|c|c|}
\hline References & $7(2008)$ & $11(2010)$ & $12(2011)$ & $6(2005)$ & $8(2008)$ \\
\hline Country of origin & Japan & Spain & Italy & UK & Austria \\
\hline Number of cases & 104 & 111 & 482 & 425 & 369 \\
\hline Number of controls & 117 & 178 & 481 & - & - \\
\hline $\begin{array}{c}\text { Association between the SCN1A IVS5N + 5 } \\
\text { G>A polymorphism and CBZ-resistant epilepsy }\end{array}$ & positive & negative & negative & - & - \\
\hline p Value & 0.04 & 0.5481 & 0.437 & - & - \\
\hline $\begin{array}{c}\text { Influence of the rs3812718 polymorphism on } \\
\text { the dosage requirements of CBZ }\end{array}$ & negative & - & - & positive & negative \\
\hline p Value & 0.83 & - & - & 0.0051 & 0.11 \\
\hline
\end{tabular}

$\mathrm{kDa})$ pore-forming $\alpha$-subunit and smaller accessory $\beta$-subunits [2,3]. Eleven genes, designated SCN1A through SCN11A, encode the $\alpha$ subunit, and at least three, designated SCN1B through $S C N 3 B$, encode the $\beta$-subunit [4].

A common synonymous polymorphism (SCN1A IVS5N $+5 \mathrm{G}>\mathrm{A}$ or rs3812718) exists in exon 5 of the SCN1A gene, which is associated with a requirement for maximum doses of CBZ and phenytoin [5]. Other studies have failed to establish an association between this polymorphism and dosages of CBZ and other sodium channel blockers [6-8] (Table 1).

Two alternatively spliced versions of exon 5 in the SCN1A gene are present in the genomic DNA, a "neonatal" and an "adult" version, which differ in three amino acids in the final product [5]. Normally, both exons are coexpressed in the adult brain. The neonatal exon can be drastically up-regulated under various circumstances including seizures, according to some studies [1]. The SCN1A IVS5N $+5 \mathrm{G}>\mathrm{A}$ polymorphism determines whether the neonatal or the adult version of exon 5 is incorporated into the final gene product. The wild-type $\mathrm{G}$ allele allows both exons to be expressed, whereas the mutant A allele almost abolishes expression of the neonatal exon by disrupting the consensus sequence. Thus, in individuals with the GG genotype, up to $50 \%$ of the gene transcripts include the neonatal version of exon 5, compared with an often undetectable level of the neonatal version in some subjects with the AA genotype [9]. We here report on the association of the SCN1A IVS5N $+5 \mathrm{G}>\mathrm{A}$ single nucleotide polymorphism (SNP) and epilepsy, and on the efficacy and dose-dependence of the CBZ therapy in Macedonian epileptic patients.

\section{MATERIALS AND METHODS}

We studied 147 adult Macedonian patients (63 male and 84 female, mean age $53.0 \pm 15.5$ ) on CBZ therapy (dosage interval $200-1200 \mathrm{mg} /$ day) for more than a month, had normal renal and hepatic functions, and were free of other diseases or treatments at the time of blood sample collection. The type of seizures and epileptic syndrome were classified according to the International League Against Epilepsy (ILAE) classification (Table 2). The control group consisted of 137 Macedonian subjects (67 newborns and 70 adults without any history of epilepsy).

Participation was voluntary and could be canceled by any individual at any time during the study (according to the Helsinki II declaration). The Ethics Committees of the Faculty of Pharmacy and of the Faculty of Medicine, Sts. Cyril and Methodius University, Skopje, Republic of Macedonia, approved the research protocol and all participants signed the study informed consent form.

Genomic DNA was extracted from whole blood,

Table 2. Characteristics of the patients in this study.

\begin{tabular}{|c|c|c|c|c|c|c|}
\hline & $\mathbf{n}$ & Gender & $\begin{array}{c}\text { Cryptogenic } \\
\text { Partial Epilepsy }\end{array}$ & $\begin{array}{c}\text { Symptomatic } \\
\text { Partial Epilepsy }\end{array}$ & $\begin{array}{c}\text { General } \\
\text { Epilepsy }\end{array}$ & $\begin{array}{c}\text { Other } \\
\text { Etiology }\end{array}$ \\
\hline Epilepsy patients & 147 & $63(\mathrm{M}) ; 84(\mathrm{~F})$ & 90 & 48 & 5 & 4 \\
\hline CBZ Resistant patients & 65 & $31(\mathrm{M}) ; 34(\mathrm{~F})$ & 36 & 24 & 3 & 3 \\
\hline CBZ Responsive patients & 82 & $32(\mathrm{M}) ; 50(\mathrm{~F})$ & 54 & 24 & 3 & 1 \\
\hline
\end{tabular}


using a Qiagen DNA extraction kit and the procedure recommended by the manufacturer (Qiagen AS, Oslo, Norway). The SCN1A IVS5N + $5 \mathrm{G}>$ polymorphism (rs3812718) was analyzed by allelic discrimination TaqMan assay (MxPro 3005P; Strategene, La Jolla, CA, USA) using the TagMan SNP genotyping assay according to the manufacturer's instructions (Applied Biosystems, Foster City, CA, USA).

Plasma CBZ concentration was measured using the fluorescence polarization immunoassay (TDx/ FLx system; Abbott Laboratories, Irving, TX, USA) and a high performance liquid chromatography (HPLC) method in which the separation was carried out on a Waters HPLC system with a reversed-phase column (Zorbax Extend C18, $150 \times 4.6 \mathrm{~mm}, 5 \mu \mathrm{m}$; Waters Corporation, Milford, MA, USA) using isocratic elution with acetonitrile and water $(35: 65 \mathrm{v} / \mathrm{v}$ as a mobile phase at $30^{\circ} \mathrm{C}$ ) with UV detection set at $220 \mathrm{~nm}$. The HPLC method validation followed the recommendations of European Medicinal Agency (EMA) guideline. Prior to analysis, the samples were pre-treated by solid-phase extraction procedure. In particular, plasma samples from each patient were spiked with $100 \mu \mathrm{L}$ internal standard, vortex-mixed for 30s and loaded into Oasis hydrophilic-lipophilicbalanced (HLB) cartridges (Waters Corporation) that were pre-conditioned with $1 \mathrm{~mL}$ methanol/water. This was followed by washing with $1 \mathrm{~mL} \mathrm{5 \%}$ methanol and elution with $1 \mathrm{~mL}$ of absolute methanol.

We defined drug responsiveness as a complete seizure-free history for at least 1 year of treatment with CBZ, and drug resistance as the occurrence of at least four seizures over 1 year of the treatment with CBZ. For the purpose of our investigation, individual therapeutic dose is a dose of a given drug that has not been changed for two or more consecutive visits in the history of the patient's treatment. The individual therapeutic doses defined as above, were compared with individual patient's genotypes. For normalization of doses, we calculated the dose ratio [dose ratio $=$ prescribed daily dose (PDD)/defined daily dose (DDD) according to the Anatomical Therapeutical Chemical Classification System (ATC) classification. The index of comparison (CBZ daily dose/CBZ plasma level) was calculated for comparison of CBZ dosages and plasma levels of individual patients.

The Hardy-Weinberg equilibrium for the SNP was determined using an online calculator (http:// ihg2. helmholtz-muenchen.de/cgi-bin/hw/hwa1.pl). Evaluation of the association between categorical variables (CBZ doses, CBZ index of comparison and patient genotype) was performed using Chisquare. Student's $t$-test $(p<0.05)$ and $z$-test (for large samples $>30$ ) were used to compare the CBZ responsiveness doses between patients with different genotypes (AA/AG; AA/GG and AG/GG).

\section{RESULTS}

The genotypes of drug-resistant and drugresponsive groups and of control group were in Hardy-Weinberg equilibrium. The genotypic frequencies of the polymorphism in all patients were 0.20 for GG, 0.52 for AG and 0.28 for the AA genotype, respectively (Table 3 ). In the control group, the distribution was $0.21,0.49$ and 0.29 for GG, AG and AA, respectively. There were no significant differences in the allelic frequencies and genotype distribution between patients and controls $(p=0.94)$.

Genotype frequencies in the CBZ-responsive group were $0.23,0.47$ and 0.30 , while those in the CBZ-resistant patients were $0.15,0.59$ and 0.26 for the GG, GA and AA, respectively. There were no statistically significant difference between these two groups $(p=0.55)$ (Table 3$)$.

Patients with the AA genotype needed a higher

Table 3. Allele and genotype distribution in epilepsy patients and controls in this study.

\begin{tabular}{|c|c|c|c|c|c|c|c|c|c|}
\hline & \multicolumn{2}{|c|}{ Allele } & & & \multicolumn{3}{c|}{ Genotype } & & \\
\hline & $\mathrm{G}$ & $\mathrm{A}$ & $95 \% \mathrm{CI}$ & $p$ Value & $\begin{array}{c}\mathrm{G} \\
\mathrm{G}\end{array}$ & $\begin{array}{c}\mathrm{G} \\
\mathrm{A}\end{array}$ & $\begin{array}{c}\mathrm{A} \\
\mathrm{A}\end{array}$ & $95 \mathrm{CI} \%$ & $p$ Value \\
\hline Epilepsy patients & $\begin{array}{c}135 \\
(45.9)\end{array}$ & $\begin{array}{c}159 \\
(54.1)\end{array}$ & $\begin{array}{c}0.997 \\
(0.717-1.388)\end{array}$ & & $\begin{array}{c}29 \\
(0.20)\end{array}$ & $\begin{array}{c}77 \\
(0.52)\end{array}$ & $\begin{array}{c}41 \\
(0.28)\end{array}$ & $\begin{array}{c}0.976 \\
(0.497-1.915)\end{array}$ & \\
\hline Controls & $\begin{array}{c}126 \\
(45.99)\end{array}$ & $\begin{array}{c}148 \\
(54.01)\end{array}$ & $\begin{array}{c}1.003 \\
(0.721-1.395)\end{array}$ & 0.98722 & $\begin{array}{c}29 \\
(0.21)\end{array}$ & $\begin{array}{c}68 \\
(0.496)\end{array}$ & $\begin{array}{c}40 \\
(0.294)\end{array}$ & $\begin{array}{c}1.025 \\
(0.522-2.012)\end{array}$ & 0.94278 \\
\hline CBZ Resistant patients & $\begin{array}{c}76 \\
(0.47)\end{array}$ & $\begin{array}{c}86 \\
(0.53)\end{array}$ & $\begin{array}{c}1.093 \\
(0.689-1.735)\end{array}$ & & $\begin{array}{c}19 \\
(0.23)\end{array}$ & $\begin{array}{c}38 \\
(0.47)\end{array}$ & $\begin{array}{c}24 \\
(0.30)\end{array}$ & $\begin{array}{c}1.346 \\
(0.502-3.608)\end{array}$ & \\
\hline $\begin{array}{c}\text { CBZ Responsive } \\
\text { patients }\end{array}$ & $\begin{array}{c}59 \\
(0.45)\end{array}$ & $\begin{array}{c}73 \\
(0.55)\end{array}$ & $\begin{array}{c}0.915 \\
(0.577-1.451)\end{array}$ & 0.70443 & $\begin{array}{c}10 \\
(0.15)\end{array}$ & $\begin{array}{c}39 \\
(0.59)\end{array}$ & $\begin{array}{c}17 \\
(0.26)\end{array}$ & $\begin{array}{c}0.743 \\
(0.277-1.992)\end{array}$ & 0.55449 \\
\hline
\end{tabular}


Table 4. Distribution of CBZ dose in CBZ-responsive patients with the AA+AG vs. GG genotypes.

\begin{tabular}{|c|c|c|c|c|c|c|c|c|c|}
\hline \multirow[t]{2}{*}{ Genotype } & \multicolumn{6}{|c|}{ Daily CBZ Dose } & \multirow[b]{2}{*}{ Total } & \multirow[b]{2}{*}{$\bar{Z}$} & \multirow[b]{2}{*}{$Z_{1-\alpha}$} \\
\hline & $200 \mathrm{mg}$ & $400 \mathrm{mg}$ & $600 \mathrm{mg}$ & $800 \mathrm{mg}$ & $1000 \mathrm{mg}$ & $1200 \mathrm{mg}$ & & & \\
\hline $\mathbf{A A}+\mathbf{A G}$ & 5 & 26 & 11 & 15 & 2 & 3 & 62 & & \\
\hline GG & 3 & 11 & 2 & 2 & 0 & 1 & 19 & & \\
\hline Total & 8 & 37 & 13 & 17 & 2 & 4 & 81 & 1.57073 & 1.435 \\
\hline
\end{tabular}

average maintenance dose of CBZ (608 $\pm 273 \mathrm{mg} /$ day) than patients with the AG and GG genotypes $(542 \pm 241$ and $468 \pm 241 \mathrm{mg} /$ day, respectively) (Figure 1). The values modes of CBZ doses were: $394 \mathrm{mg} /$ day for GG, $400 \mathrm{mg} /$ day for AG and 450 $\mathrm{mg} /$ day for AA genotypes. These values were interdependent $\left[\chi^{2}=4.965>\chi_{4: 0 ; 30}^{2}=4.878 ; \alpha=0.30\right.$ and $\mathrm{k}=(3-1)(3-1)=4)$ but the differences were not statistically significant $(p=0.05)$. We found a significant statistical difference when we compared $\mathrm{AA}+\mathrm{AG}$ vs. GG genotype $\left(\mathrm{z}=1.57073>\mathrm{z}_{1-\alpha}=\right.$ 1.435; $\alpha=0.15$ ) (Table 4).

These results indicate that the likelihood of a positive response to $\mathrm{CBZ}$ therapy at an initial dose of $400 \mathrm{mg}$ is $41.67,57.89$ and $73.68 \%$ in patients with AA, AG and GG genotypes, respectively. These differences persist only up to a dose of 1000 $\mathrm{mg} /$ day, after which there is no difference between patients with different genotypes (Figure 2). The total CBZ plasma concentrations and their correlation with the patients' genotype showed interdependence $\left(x^{2}=11.610>\chi_{10 ; 0 ; 32}^{2}=11.5 ; \alpha=0.32\right.$ and $\mathrm{k}=(6-1)$ $(3-1)=10)$. Distribution of dose ratios (PDD/DDD) in patients with different genotypes are presented in Figure 3.

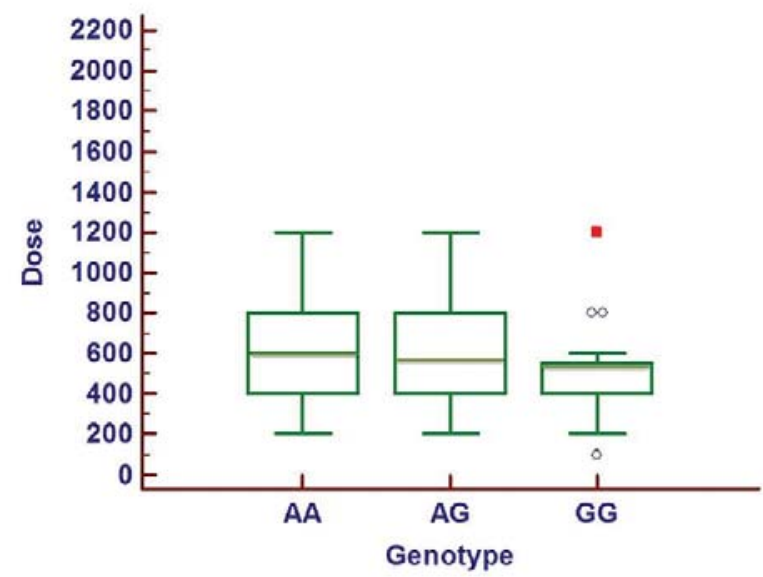

Figure 1. Comparison of therapeutic daily $\mathrm{CBZ}$ dose (mg) in CBZ responsive patients with different SCN1A genotypes.
The ratio of daily doses of $\mathrm{CBZ}$ divided by plasma CBZ levels (dose/level) of patients with the AA genotype was $24.95 \pm 11.08$, and $22.09 \pm 8.45$ and $20.62 \pm 8.59$ for the AG and GG genotypes, respectively. These results also showed interdependence $\left(\chi^{2}=11.88>\chi_{10 ; 0 ; 30}^{2}=11.781 ; \alpha=0.30\right.$ and $\mathrm{k}=(6-1)$ $(3-1)=10)$, indicating that the differences were primarily exerted at the level of target responsiveness. This was further strengthened by the lack of statistically significant difference in CBZ plasma levels between patients with different genotypes treated with the same CBZ dose (Figure 4).

\section{DISCUSSION}

Our results showed that the frequency of this polymorphism in our patients is similar to that in other population studies [10]. The lack of an association between this polymorphism and the responsiveness to $\mathrm{CBZ}$ therapy in our patients did not confirm the findings of recent reports $[5,11]$ but confirmed those of one other study [12] (Table 1). These discrepancies may be explained by factors, including sample size, differences in ethnic background of populations, differences in dosing strategies or etiologies of the

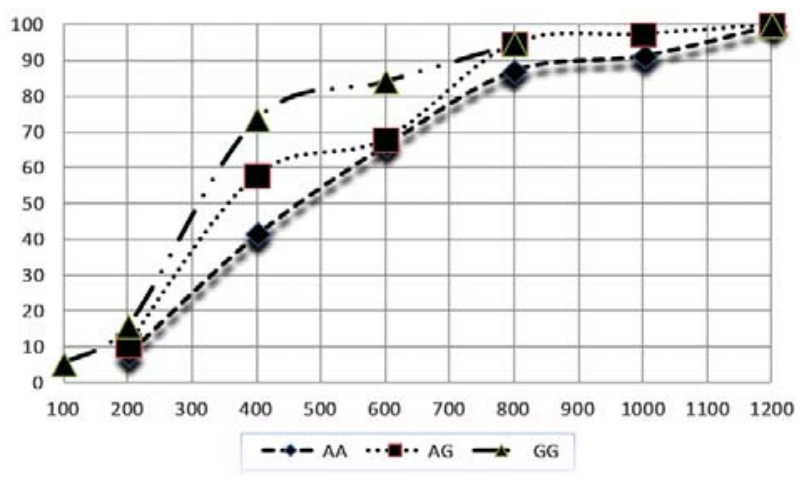

Figure 2. Likelihood of a positive response to CBZ therapy between patients with different genotypes. 


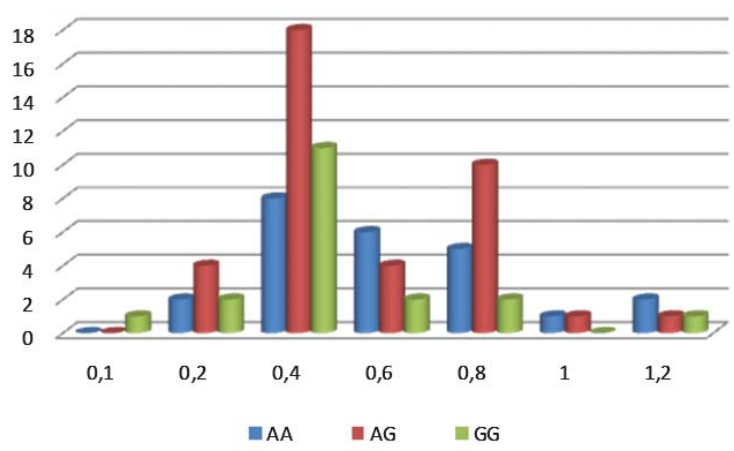

Figure 3. Distribution of $\mathrm{CBZ}$ doses, expressed as dose ratios (PDD/DDD), for SCN1A IVS5N + $5 \mathrm{G}>\mathrm{A}$ genotypes.

epilepsy of the studied patients.

Patients with the AA genotype needed a higher maintenance dose of CBZ (608 $\pm 273 \mathrm{mg} /$ day) than patients with the AG and GG genotypes (542 \pm 241 and $468 \pm 241 \mathrm{mg} /$ day, respectively). These findings showed interdependence, but did not reach statistical significance, probably because of the insufficient number of patients included in the study. The average dose of CBZ needed for a seizure-free period, total plasma concentration of CBZ and dose index were highest in homozygotes for the A allele, indicating that the A allele is a recessive trait that determines the efficacy of CBZ therapy. These results are similar to those of several large studies [8]. Several in vitro or in vivo studies have demonstrated that the A allele abolished production of the neonatal version of SCN1 A channels [9] and that the adult SCN1A channels present in AA homozygotes, have significantly lower sensitivity to CBZ $[5,6]$, which would explain the requirements for higher maintenance doses in our patients.

Our results have revealed a difference in the likelihood of response to CBZ, especially at a lower dose, between patients with different genotypes but these differences are difficult to translate into clear clinical recommendations. Moreover, the overlap in responses of patients with different genotypes, indicate that other factors also influenced CBZ response in our patients. Several other genetic variants in this gene and in other genes related to CBZ metabolism or transport have been described, which may provide further information as to a potential clinical benefit of pharmacogenetic testing as a tool for individualized therapy in patients with epilepsy $[1,13]$.

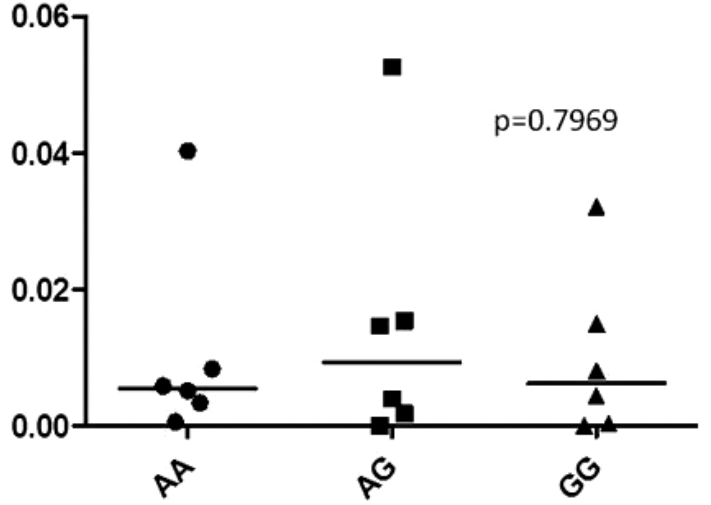

Figure 4. Distribution of total CBZ plasma concentrations $(\mathrm{mmol} / \mathrm{L})$ in patients with different genotypes treated with a daily CBZ dose of $400 \mathrm{mg}$.

Larger clinical studies having the statistical power to evaluate the impact of all these variables are warranted to clarify this issue.

\section{REFERENCES}

1. Löscher W, Klotz U, Zimprich F, Schmidt D. The clinical impact of pharmacogenetics on the treatment of epilepsy. Epilepsia. 2009; 50(1): 1-23.

2. Yu FH, Catterall WA. Overview of the voltage-gated sodium channel family. Genome Biol. 2003; 4(3): 207.

3. George AL Jr. Inherited disorders of voltage-gated sodium channels. J Clin Invest. 2005; 115(8): 19901999.

4. Plummer NW, Meisler MH. Evolution and diversity of mammalian sodium channel genes. Genomics. 1999; 57(2): 323-331.

5. Tate SK, Depondt C, Sisodiya SM, Cavalleri GL, Schorge S, Soranzo N, Thom M, Sen A, Shorvon SD, Sander JW, Wood NW, Goldstein DB. Genetic predictors of the maximum doses patients receive during clinical use of the anti-epileptic drugs carbamazepine and phenytoin. Proc Natl Acad Sci USA. 2005; 102(15): 5507-5512.

6. Tate SK, Singh R, Hung CC, Tai JJ, Depondt C, Cavalleri GL, Sisodiya SM, Goldstein DB, Liou HH. A common polymorphism in the SCN1A gene associates with phenytoin serum levels at maintenance dose. Pharmacogenet Genomics. 2006; 16(10): 721-726.

7. Abe $T$, Seo $T$, Ishitsu $T$, Nakagawa $T$, Hori $M$, Nakagawa K. Association between SCN1A polymorphism and carbamazepine-resistant epilepsy. $\mathrm{Br}$ J Clin Pharmacol. 2008; 66(2): 304-307.

8. Zimprich F, Stogmann E, Bonelli S, Baumgartner C, Mueller JC, Meitinger, T, Zimprich A, Strom TM. A functional polymorphism in the SCN1A gene is not associated with carbamazepine dosages in Austrian patients with epilepsy. Epilepsia. 2008; 49(6): 1108-1109. 
9. Heinzen EL, Yoon W, Tate SK, Sen A, Wood NW, Sisodiya SM, Goldstein DB. Nova2 interacts with a cis-acting polymorphism to influence the proportions of drug-responsive splice variants of SCN1A. Am J Hum Genet. 2007; 80(5): 876-883.

10. Thompson CH, Kahlig KM, George AL Jr. SCN1A splice variants exhibit divergent sensitivity to commonly used antiepileptic drugs. Epilepsia. 2011; 52(5): 1000-1009.

11. Sánchez MB, Herranz JL, Leno C, Arteaga R, Oterino A, Valdizán EM, Nicolás JM, Adín J, Armijo JA. Genetic factors associated with drug-resistance of epilepsy: relevance of stratification by patient age and aetiology of epilepsy. Seisure. 2010; 19(2): 93-101.
12. Manna I, Gambardella A, Bianchi A, Striano P, Tozzi R, Aguglia U, Beccaria F, Benna P, Campostrini R, Canevini MP, Condino F, Durisotti C, Elia M, Giallonardo AT, Iudice A, Labate A, La Neve A, Michelucci R, Muscas GC, Paravidino R, Zaccara G, Zucca C, Zara F, Perucca E. A functional polymorphism in the SCN1A gene does not influence antiepileptic drug responsiveness in Italian patients with focal epilepsy. Epilepsia. 2011; 52(5): $1528-1167$.

13. Depondt $C$. The potential of pharmacogenetics in the treatment of epilepsy. Eur J Paediatr Neurol. 2006; 10(2): 57-65. 